\title{
Impact of methane and black carbon mitigation on forcing and temperature: a multi-model scenario analysis
}

\author{
Steven J Smith ${ }^{1}$ (D) Jean Chateau ${ }^{2} \cdot$ Kalyn Dorheim $^{1} \cdot$ Laurent Drouet $^{3}$. \\ Olivier Durand-Lasserve ${ }^{2}$. Oliver Fricko ${ }^{4}$ Shinichiro Fujimori ${ }^{5,6} \cdot$ Tatsuya Hanaoka $^{6}$. \\ Mathijs Harmsen ${ }^{7,8}$ • Jérôme Hilaire ${ }^{9,10}$. Kimon Keramidas ${ }^{11}$ - Zbigniew Klimont ${ }^{4}$. \\ Gunnar Luderer $^{9}$ - Maria Cecilia P. Moura ${ }^{1}$ - Keywan Riahi ${ }^{4}$ • Joeri Rogelj ${ }^{12,4}$. \\ Fuminori Sano ${ }^{13}$. Detlef P. van Vuuren ${ }^{7,8} \cdot$ Kenichi Wada ${ }^{13}$
}

Received: 27 August 2019 / Accepted: 7 July 2020 / Published online: 17September2020

(C) Battelle Memorial Institute 2020

\begin{abstract}
The relatively short atmospheric lifetimes of methane $\left(\mathrm{CH}_{4}\right)$ and black carbon $(\mathrm{BC})$ have focused attention on the potential for reducing anthropogenic climate change by reducing Short-Lived Climate Forcer (SLCF) emissions. This paper examines radiative forcing and global mean temperature results from the Energy Modeling Forum (EMF)-30 multimodel suite of scenarios addressing $\mathrm{CH}_{4}$ and $\mathrm{BC}$ mitigation, the two major short-lived climate forcers. Central estimates of temperature reductions in 2040 from an idealized scenario focused on reductions in methane and black carbon emissions ranged from 0.18 $0.26^{\circ} \mathrm{C}$ across the nine participating models. Reductions in methane emissions drive $60 \%$ or more of these temperature reductions by 2040 , although the methane impact also depends on auxiliary reductions that depend on the economic structure of the model. Climate model parameter uncertainty has a large impact on results, with SLCF reductions resulting in as much as $0.3-0.7^{\circ} \mathrm{C}$ by 2040 . We find that the substantial overlap between a SLCF-focused policy and a stringent and comprehensive climate policy that reduces greenhouse gas emissions means that additional SLCF emission reductions result in, at most, a small additional benefit of $\sim 0.1^{\circ} \mathrm{C}$ in the $2030-2040$ time frame.
\end{abstract}

Keywords Climate change $\cdot$ Air pollution $\cdot$ Radiative forcing $\cdot$ Black carbon $\cdot$ Methane

This article is part of a Special Issue reporting results from the "Energy Modeling Forum (EMF)-30 Study on Short-Lived Climate Forcers (SLCF) and Air Quality” edited by John Weyant, Steven J Smith, and Zbigniew Klimont

Electronic supplementary material The online version of this article (https://doi.org/10.1007/s10584-02002794-3) contains supplementary material, which is available to authorized users.

Steven J Smith ssmith@pnnl.gov

Extended author information available on the last page of the article 


\section{Introduction}

While the predominant driver of anthropogenic climate change is fossil fuel carbon dioxide $\left(\mathrm{CO}_{2}\right)$ emissions, emissions of other greenhouse gases (GHGs) and air pollutants also impact the climate (Myhre et al. 2013). Interest has focused lately on forcing agents with shorter atmospheric lifetimes, so-called short-lived climate forcers (SLCFs), mitigation of which offers the potential for near-term climate-mitigation. SLCF policies are potentially important because they could contribute to mitigating global warming in the short term and, to some extent, offset climate system inertia.

When evaluating the relative importance of different emission species, it is important to consider both direct effects on climate and various indirect effects. The two most important warming SLCFs are methane $\left(\mathrm{CH}_{4}\right)$ and black carbon $(\mathrm{BC})$, as shown in Table 1 adapted from Myhre et al. (2013). Methane is the second most important greenhouse gas in terms of its current contribution to radiative forcing. The direct forcing from methane is amplified due to increases in tropospheric ozone and stratospheric water vapor (Table 1). Black carbon, often referred to as soot, also increases warming, although the magnitude of its effect is highly uncertain (Bond et al. 2013) and could be smaller than currently estimated (Stjern et al. 2017).

While SLCF analysis has often focused on emissions that result in warming, whose reduction would reduce temperature changes, it is critical to include all emissions species since some co-emitted species have cooling effects that could offset reductions in methane and black carbon. The combination of sulfur dioxide and aerosol-cloud indirect forcing may have a cooling effect that is of the same order of magnitude as the forcing from black carbon and methane combined (Table 1). Co-emitted air pollutants also contribute additional net positive forcing through increases in tropospheric ozone and carbon dioxide concentrations, which is offset somewhat by a net decrease in methane lifetime.

Early estimates of the potential climate impact of SLCF reductions (UNEP 2011; Ramanathan and Xu 2010; Shindell et al. 2012; Hu et al. 2013) indicated that a focus on reducing SLCF emissions could reduce warming by around $0.5^{\circ} \mathrm{C}$. These estimates not only drew on different reference scenarios with higher SLCF mitigation potentials (addressing also $\mathrm{BC}$ sources in addition to transport and residential sectors) but also used simple impulse models for climate response, or made simplified assumptions about the development of some species beyond 2030 (see discussion in Smith and Mizrahi 2013). Subsequent analysis, e.g., using integrated assessment models together with simple climate models (Smith and Mizrahi 2013; Rogelj et al. 2014a), and updated reference and mitigation scenarios in a study using multiple atmospheric models (e.g., Stohl et al. 2015) found smaller temperature changes for

Table 1 Radiative forcing ( $E R F$ effective radiative forcing) by emitted compound over 1750-2011 from Fig. 8.17 of Myhre et al. (2013). ERFaci is aerosol-cloud interactions (also termed cloud indirect effects). See SM $\S D$ for additional details

\begin{tabular}{lc}
\hline Emission & Forcing $\left(\mathrm{ERF} \mathrm{W} / \mathrm{m}^{2}\right)$ \\
\hline $\mathrm{CO}_{2}$ & 1.68 \\
$\mathrm{CH}_{4}$ & 0.97 \\
Other GHGs & 0.38 \\
$\mathrm{BC}+\mathrm{OC}$ & 0.35 \\
$\mathrm{SO}_{2}, \mathrm{NH}_{3}$, and ERFaci & 0.92 \\
Reactives & 0.18 \\
Total & 2.64 \\
\hline
\end{tabular}


SLCF reductions, especially with respect to the global mean temperature response to $\mathrm{BC}$ mitigation.

There is a need, therefore, to examine the emissions and climate system responses to SLCFfocused reductions across a range of both emission projection models and climate system responses. This paper examines the radiative forcing and temperature impact of methane- and black carbon-focused reductions within the multi-model suite of idealized scenarios developed as part of the Energy Modeling Forum (EMF)-30 model comparison project focusing on Short-Lived Climate Forcers and Air Quality (hereafter EMF-30). ${ }^{1}$ Radiative forcing is the energy imbalance at the top of the atmosphere, relative to pre-industrial conditions, that is caused by a change in atmospheric concentrations. Examining radiative forcing is a useful method of comparing the relative contributions of various greenhouse gases and other forcing agents such as aerosols. For example, we compare the impact of changes in $\mathrm{CO}_{2}$ emissions, methane emissions, and aerosol emissions.

Ultimately, however, we are interested not in changes in forcing, but climate changes that might impact human and natural systems. Therefore, we also examine global surface temperature changes. Changes in other quantities, such as precipitation and changes in extremes or regional temperature, might also be of interest but would require other tools. We note that for black carbon, the relationship between forcing and surface temperature changes is particularly uncertain, an issue that we return to in the discussion.

This analysis centers on a subset of scenarios that illustrate the potential impact of methaneand black carbon-focused reductions separately, then jointly, and finally in combination with comprehensive reductions in greenhouse gas emissions. The use of multiple integrated assessment models is a key feature of this study as this allows the examination of selfconsistent scenarios where components of the system interact with each other. This is particularly important when considering the interplay between SLCF-focused and GHGfocused policies. The multi-model analysis of this suite of scenarios allows us to identify results that are robust across the models and assess underlying factors that cause model results to differ. Our analysis uses a comprehensive methodology from emissions to global climate so that the impacts of all emitted species can be considered (Table 1), along with uncertainty.

While we focus in this analysis on SLCF emissions, it is important to note that reducing the level of future climatic changes requires reductions in carbon dioxide emissions. Unlike SLCFs, carbon dioxide accumulates in the atmosphere, meaning that stabilizing radiative forcing means ultimately reducing net carbon dioxide emissions to zero. We, therefore, also include scenarios with comprehensive greenhouse gas reductions in the analysis as discussed below.

The role of SLCF emissions in a longer-term context has recently been reviewed by Rogelj et al. (2018) as part of the IPCC special report on $1.5^{\circ}$ warming. They note that both geophysical uncertainties (e.g., parameter uncertainties we explore below) and uncertainty in long-term SLCF mitigation potential can have a significant impact on the allowable carbon dioxide emissions budget for $1.5^{\circ}$ warming. In contrast, we focus here on the impact of SLCF emission reductions over the next several decades and will return to this point in the discussion.

This analysis of radiative forcing and temperature results is accompanied by other topical papers in this special issue including analysis of scenarios that reduce methane (Harmsen et al. 2019a, this issue) and an analysis of the potential for SLCF-focused reductions to contribute toward meeting climate targets as an adjunct to nationally determined contributions (NDCs)

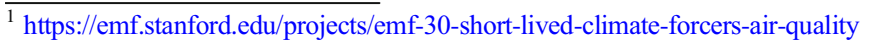


(Harmsen et al. 2019b, this issue). An overview paper (Smith et al., in prep, this issue) will present the overall study design and a synthesis of results from both topical papers and additional analysis papers by individual modeling groups.

The scenarios and a brief overall description of the models are provided in the next section. A more comprehensive description of the EMF-30 exercise and the associated models is provided in the supplementary material (SM). The remaining sections of this paper examine results for forcing and then surface temperature change. Given the substantial uncertainty in climate parameters, the results from a probabilistic analysis are also presented. The paper concludes with a discussion.

\section{Methods}

The nine models participating in the EMF-30 exercise are as follows: AIM/CGE, DNE21+ v.14, ENV-Linkages, GCAM4, IMAGE, MESSAGE-GLOBIOM, POLES, REMIND, and WITCH (see SM). These models span a range of computational methodologies and model structures. All the model versions used in this study incorporate emissions of the major greenhouse gases $\left(\mathrm{CO}_{2}, \mathrm{CH}_{4}, \mathrm{~N}_{2} \mathrm{O}\right)$, and a suite of air pollutant and precursor emissions including nitrogen oxides $\left(\mathrm{NO}_{x}\right)$, carbon monoxide $(\mathrm{CO})$, non-methane hydrocarbons (NMVOC), sulfur dioxide $\left(\mathrm{SO}_{2}\right)$, black carbon (BC), and organic carbon (OC).

All radiative forcing and temperature calculations presented in this work use a common version of the simple climate model MAGICC6 (Meinshausen et al. 2011a,b). MAGICC6 incorporates representations of the relevant gas cycles and radiative forcing for each species. Critically, MAGICC6 includes a multi-region representation of forcing and climate responses. This results in a more rapid response of the climate system to aerosol forcings, located predominately over land and in the northern hemisphere such as sulfate and black carbon (Schwarber et al. 2018), as also seen in earth system models (Shindell 2014). The use of a common climate model eliminates spurious differences due to different climate model versions and parameter assumptions used by individual modeling groups. We specifically report here MAGICC6 results for top of the atmosphere forcing after stratospheric adjustment (see supplementary material, SM, §C for further discussion).

Models participating in the EMF-30 exercise implemented a wide range of scenarios, some of which are more fully explored in other papers in this special issue (Harmsen et al. 2019a). Each model first produces a reference scenario, generally following socio-economic assumptions similar to the SSP2 storyline (O'Neill et al. 2017), representing future conditions without additional climate policies. Each model's reference case also includes some representation of on-going efforts to limit air pollutant emissions. Differences in reference case trajectories, which are not harmonized between the models, contribute to differences in model results. This is a useful feature as we seek robust results across this diversity of models.

Under the EMF-30 exercise, a common set of scenarios was implemented in nine models that span a range of methodologies. We focus in this analysis on the differences from the reference case scenario for five scenarios, summarized in Table 2. The first two scenarios target mitigation of selected SLCFs: CH4-Only - incorporates only policies to reduce methane emissions; BCOC-EndU-explores BC and OC reductions achievable by application of best available technology in the transportation sector and the phase-out of direct use of biomass and coal in the residential and commercial buildings sector. These two sectors represent the majority of anthropogenic emissions of $\mathrm{BC}$ and $\mathrm{OC}$ worldwide for nearly all 
Table 2 Overview of scenarios used in this work. See Supplemental Material (SM) for further details

\begin{tabular}{|c|c|c|}
\hline Scenario name & General description & SLCF assumptions \\
\hline Reference & $\begin{array}{l}\text { Reference case without additional } \\
\text { climate policies. }\end{array}$ & $\begin{array}{l}\text { Air pollutant emission controls evolve according } \\
\text { to either a reference scenario or current } \\
\text { legislation (CLE) approach (see discussion in } \\
\text { SM), with no specific focus on SLCF emis- } \\
\text { sions. }\end{array}$ \\
\hline CH4-Only & $\begin{array}{l}\text { Maximal feasible reductions in } \\
\text { methane }\left(\mathrm{CH}_{4}\right) \text { emissions }\end{array}$ & $\begin{array}{l}\text { Implements a } \mathrm{CH}_{4} \text { price that ramps up from zero } \\
\text { in } 2015 \text { to } \$ 4250 / \mathrm{tCH} 4 \text { by } 2030 \text {, constant } \\
\text { thereafter. This policy is considered to be of } \\
\text { sufficient magnitude to induce near maximal } \\
\text { reductions in methane emissions. }{ }^{a}\end{array}$ \\
\hline BCOC-EndU & $\begin{array}{l}\text { Maximal reductions of } \mathrm{BC} \text { and } \mathrm{OC} \\
\text { emissions from transportation and } \\
\text { building sectors }\end{array}$ & $\begin{array}{l}\text { Phase out end-use coal and biomass consumption } \\
\text { in buildings (roughly equivalent to } 100 \% \text { pen- } \\
\text { etration of clean cook-stoves and heating). Be- } \\
\text { gin implementation of advanced emission } \\
\text { controls in transportation for all regions, } \\
\text { starting after } 2015 \text { similar to LIMITS Maximal } \\
\text { Feasible Reduction (MFR) } 2030 \text { in OECD re- } \\
\text { gions. } b\end{array}$ \\
\hline SLCF & $\begin{array}{l}\text { Both BCOC-EndU and CH4-Only } \\
\text { policies }\end{array}$ & $\begin{array}{l}\text { As above for both } \mathrm{CH}_{4} \text { in all sectors and } \mathrm{BC} \mathrm{OC} \text { in } \\
\text { buildings and transportation. }\end{array}$ \\
\hline ClimPolicy & $\begin{array}{l}\text { Global policy to reduce greenhouse gas } \\
\text { (GHG) emissions }\end{array}$ & $\begin{array}{l}\text { Global cumulative fossil } \mathrm{CO}_{2} \text { emissions constraint } \\
\text { of } 1000 \mathrm{GtCO}_{2} \text { from } 2011 \text { to } 2100 \text {. This budget } \\
\text { corresponds to the upper end of emission } \\
\text { budgets of scenarios in the } 430-480 \mathrm{ppm} \text { cate- } \\
\text { gory of likely } 2{ }^{\circ} \mathrm{C} \text { scenarios and is also used in } \\
\text { the ADVANCE/IAMC community diagnostics } \\
\text { exercise. }{ }^{c}\end{array}$ \\
\hline ClimPolicy+SLCF & $\begin{array}{l}\text { ClimPolicy and SLCF scenarios } \\
\text { together }\end{array}$ & Both SLCF and ClimPolicy scenarios applied. \\
\hline
\end{tabular}

\begin{abstract}
a For reference, this is equal to $\$ 50 / \mathrm{tCO} 2$ and methane index of 85 (=20-year AR5 GWP), or also equal to $\$ 170$ / tCO2 and a methane index of 25 (=100-year AR4 value). The GWP is given for reference only-whatever index or other formulation for $\mathrm{CO}_{2}$ equivalence implemented within each model has been used ${ }^{\mathrm{b}}$ Both building and transport policies are completed by 2030 . The intention of this scenario is that all road vehicles in use by 2030 would be in compliance with strict emission controls with no super-emitters. Energy system feedbacks (e.g., energy technology replacement to provide the services formally supplied by coal and biomass) are included in the results ${ }^{\mathrm{c}}$ Carbon price is also applied, as implemented for each model, to non- $\mathrm{CO}_{2} \mathrm{GHG}$ emissions. Models vary in how $\mathrm{CO}_{2}$ emission policies are applied to land-use $\mathrm{CO}_{2}$ emissions. Models with a time horizon until 2050 also applied a 2011-2050 budget of $1000 \mathrm{GtCO}_{2}$, implicitly assuming carbon neutrality for the 2 nd half of the century
\end{abstract}

regions and are also well represented in the models. Finally, the large BC/OC ratio in the transportation sector makes this potentially an even more attractive target for climate mitigation. In order to assess the impact of strong reduction of methane and black carbon jointly, the SLCF scenario is evaluated - it combines CH4-Only and BCOC-EndU. For comparison, we include an idealized climate policy scenario (ClimPolicy) in which emissions of all GHGs, including $\mathrm{CH}_{4}$, are reduced such that cumulative $\mathrm{CO}_{2}$ emissions over 2011-2100 are equal to $1000 \mathrm{Gt} \mathrm{CO}_{2}$, generally sufficient to limit warming below $2{ }^{\circ} \mathrm{C}$ with $>67 \%$ probability (Luderer et al. 2018). Finally, in the ClimPolicy+SLCF scenarios, both GHG reductions and SLCF-focused reductions are applied so we can evaluate the additional impact of SLCF reductions relative to the ClimPolicy scenario. 


\section{Radiative forcing changes}

\subsection{Overall results}

Figure 1a shows 2040 and 2050 changes in global radiative forcing for each scenario relative to each model's reference scenario using central climate model parameters (see SM for 2030 and 2050). As found in previous work (Smith and Mizrahi 2013; Rogelj et al. 2014b), the major SLCF contributor to radiative forcing changes is methane reductions (e.g., the CH4-Only scenario). The BCOC-EndU scenario, focused on $\mathrm{BC}$ reductions, results in a net reduction in most models; however, they are significantly smaller than for CH4-Only. There is little sectoral or species overlap in the $\mathrm{CH}_{4}$ - and $\mathrm{BC}$-reduction scenarios, with the sum of CH4-Only and BCOC-EndU forcing reductions close to the reductions in combined SLCF scenario.

The reduction in total forcing from the SLCF scenario is similar to that from the ClimPolicy scenario in 2030 (see SM), but from 2040 onward, the ClimPolicy scenario results in much larger forcing reductions. There is considerable overlap in terms of sectoral and emission species reduction between the ClimPolicy and SLCF scenarios, which will be examined in the temperature change section below.

We split our analysis of forcing changes into consideration of the direct forcing changes, which are the forcing changes from the targeted emission species, and auxiliary reductions, which are defined as the sum of all other forcing changes that occur in other species (see SM). We now examine results for the $\mathrm{CH} 4$ and $\mathrm{BC}$ emission reduction scenarios below.
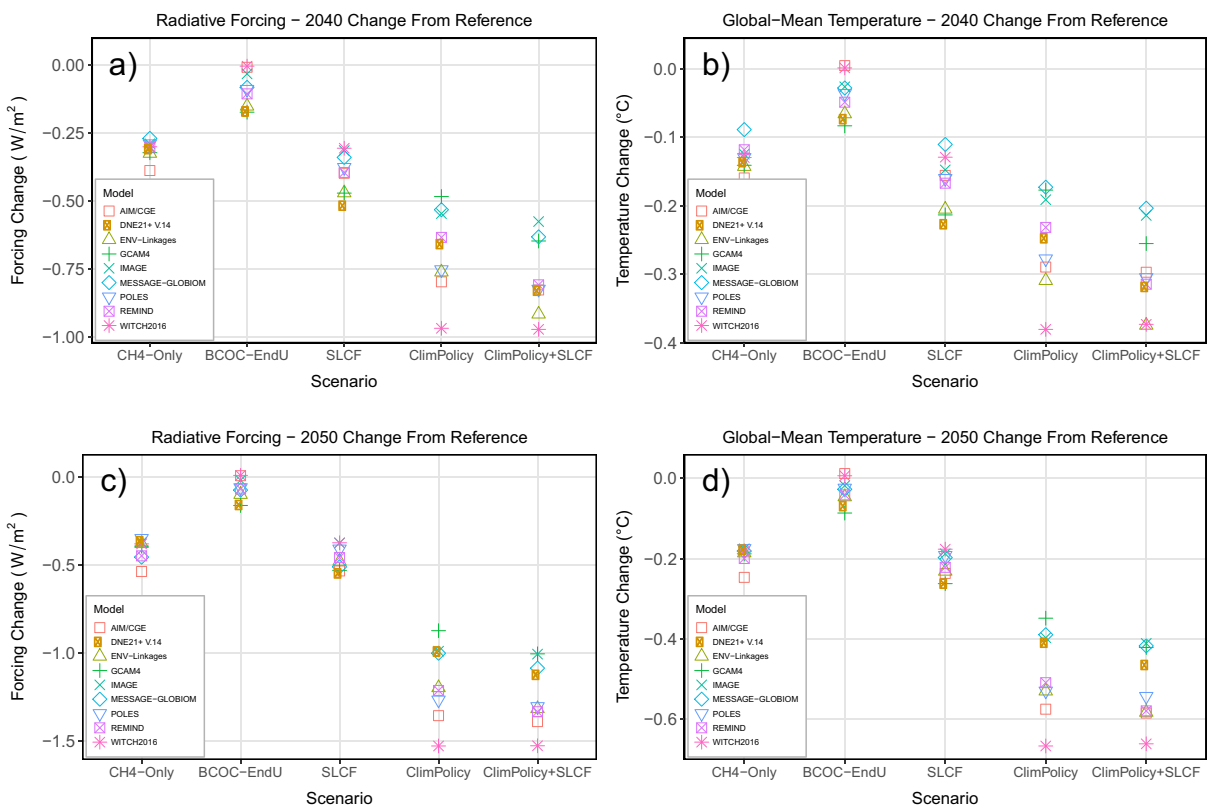

Fig. 1 a (left) Total radiative forcing and $\mathbf{b}$ (right) global-mean temperature changes relative to the corresponding reference scenario for the five central EMF-30 scenarios in 2040 and for 2050 (c and d). Each symbol represents the result from an individual model. All results estimated consistently using the same version of the MAGICC6 simple climate model. Similar figures for years 2030 and 2100 can be found in the SM, as well as larger versions of these figures 


\subsection{CH4-Only-methane-focused reductions}

In the CH4-Only scenario, a methane price is phased in from 2015 to 2030 and has been set to a magnitude sufficient to induce near-maximal reductions in methane emissions (SM §A). The methane emission reductions in the CH4-Only scenario result in an average $2040 \mathrm{CH}_{4}$ forcing a reduction of $0.23 \mathrm{~W} / \mathrm{m}^{2}$, with relatively little scatter other than one model (Fig. 2). Further analyses of methane emission reductions are provided in Harmsen et al. (2019a), although see $\mathrm{SM}$ for a note on differences in the $\mathrm{CH}_{4}$ scenario definition between these two works.

There are also significant auxiliary forcing reductions that are in addition to the change in $\mathrm{CH}_{4}$ forcing itself. The largest are reductions in $\mathrm{CO}_{2}$ and tropospheric ozone forcing (Fig. 2). Neglecting one outlier model whose results in this case are due to a specific model configuration, total auxiliary forcing reductions amplify the direct $\mathrm{CH}_{4}$ emission reductions by 30 $50 \%$ in 2040 and $35-70 \%$ in 2050 . The MESSAGE model is an outlier here due to the inclusion of land-use-related $\mathrm{CO}_{2}$ emission reductions in the $\mathrm{CH}_{4}$ reduction case. (see discussion in SM.)

The auxiliary $\mathrm{CO}_{2}$ reductions vary across the models with one group of models showing relatively small reductions $\left(<0.02 \mathrm{~W} / \mathrm{m}^{2}\right.$ in 2040) with the second group showing much larger reductions, which range from 15 to $20 \%$ of the direct reduction in $\mathrm{CH}_{4}$ forcing in 2040, and $20-50 \%$ in 2050 . The relative impact of these auxiliary $\mathrm{CO}_{2}$ reductions increases with time as $\mathrm{CO}_{2}$ concentration changes accumulate in the atmosphere.

There are two sets of mechanisms for these auxiliary effects. The first set of mechanisms are economic auxiliary effects, which are reductions due to economic feedbacks and technology

\section{Forcing Change Relative to Reference for CH4-Only}
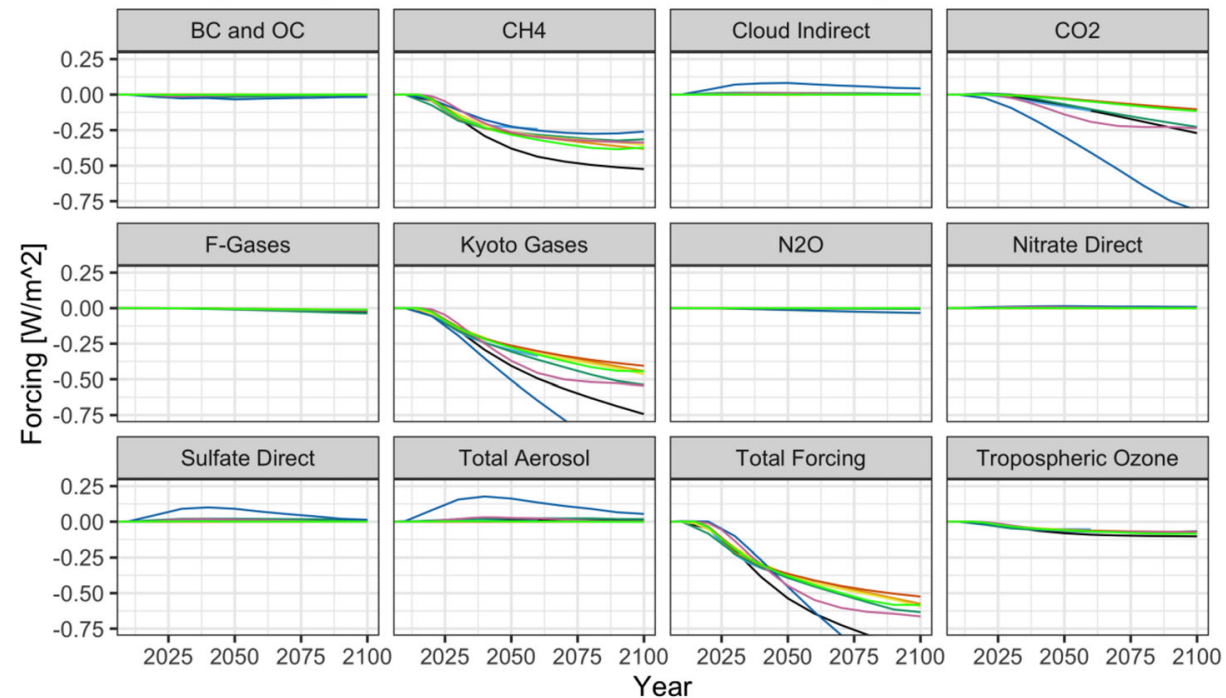

$$
\begin{array}{lll}
\text { model } & \text { - AIM/CGE } & \text { - ENV-Linkages - IMAGE }
\end{array}
$$

Fig. 2 Radiative forcing change for the $\mathrm{CH} 4-\mathrm{Only}$ scenario by component relative to the reference scenario $\left(\mathrm{F}_{\mathrm{CH} 4-\text { only }}-\mathrm{F}_{\text {Reference }}\right)$. The sum of all forcing components is shown as "Total Forcing" and all aerosols as "Aerosol". Negative values indicate net cooling in the CH4-Only scenario as compared with the reference scenario. See SM for forcing variable definitions 
shifts induced by the $\mathrm{CH}_{4}$ emission reduction policy. In some models, the methane emission price has an economic impact on the cost of activities that produce methane. As the methane price increases, those activities become more expensive and their consumption is reduced, which also can reduce other emissions such as $\mathrm{CO}_{2}$. For example, reductions in (1) fossil fuel and (2) beef production, two sectors with substantial methane emissions, would tend to reduce net $\mathrm{CO}_{2}$ emissions through reducing (1) fossil fuel consumption and (2) land-use change. The strength of these reductions will depend on model structure and the extent to which the $\mathrm{CH}_{4}$ price is passed through to consumers. Note that in some cases, these economic feedbacks can be a modeling choice and in other cases, it is inherent to the structure of the model (see model descriptions in the SM).

In four of the models, there are limited or no economic feedbacks from a methane reduction policy. This can be thought of as a $\mathrm{CH}_{4}$ policy formulation where $\mathrm{CH}_{4}$ reductions are incentivized and this is assumed to occur in a revenue neutral manner with respect to the $\mathrm{CH}_{4}$-producing activity. This might represent, for example, an offset or best available technology (BAT) regulation regime where the direct costs of methane mitigation activities are compensated but any non-mitigatable emissions are not priced. While there may still be economic feedbacks in such a regime in reality, these can be of a different magnitude (e.g., general equilibrium effects instead of direct effects at the technology level) or simply not be included in the model formulation.

A second set of auxiliary reduction mechanisms are physical effects related to changing methane concentrations. Decreasing methane emissions decreases temperatures, the oxidation of $\mathrm{CH}_{4}$ to $\mathrm{CO}_{2}$, the production of tropospheric ozone, and the production of stratospheric water vapor (all included in MAGICC). All of these forcing mechanisms contribute to the auxiliary forcing reductions and their magnitude is quantified in the lower set of model auxiliary results noted above (e.g., $\sim 0.03 \mathrm{~W} / \mathrm{m}^{2}$ in 2050). The largest contributor to the $\mathrm{CO}_{2}$ decrease is smaller carbon-cycle feedbacks due to decreased global temperatures. Note that there is additional forcing uncertainty for some of these mechanisms as compared with methane forcing itself. We also note that in the configuration used here, all anthropogenic methane is assumed to be oxidized to $\mathrm{CO}_{2}$, where in reality only fossil $\mathrm{CH}_{4}$ emissions should be considered to add to atmospheric $\mathrm{CO}_{2}$ concentration (Boucher et al. 2009), which will lead to an overestimate of the effect of $\mathrm{CH}_{4}$ oxidation.

Consideration of these auxiliary effects is clearly a potentially important element of a policy focused on $\mathrm{CH}_{4}$ emission reductions. The economic auxiliary effects are the dominant contributor, where these are included, which continue to increase throughout the century as $\mathrm{CO}_{2}$ accumulates in the atmosphere. We note that this scenario included a relatively high $\mathrm{CH}_{4}$ emission price. A different scenario formulation, with a more modest $\mathrm{CH}_{4}$ price, will result in a lower level of economic auxiliary emission reductions.

\subsection{BCOC-EndU—black carbon-focused reductions}

The BCOC-EndU scenario includes two policies targeting emission sectors with high BC emissions: a complete phase-out of end-use coal and traditional biomass in the buildings sector and the imposition of stringent particulate emission controls on vehicles, both by 2030. These $\mathrm{BC}$-focused reductions show a wide range of results across the models, with a total forcing reduction relative to reference that peaks in 2030 and ranges from $0.06-0.29 \mathrm{~W} / \mathrm{m}^{2}$. The reasons for the range in $\mathrm{BC}$ and $\mathrm{OC}$ emission reductions are discussed further by Smith et al. (in prep, this issue), so we concentrate here on examining the various radiative forcing components. 
$\mathrm{BC}$ and $\mathrm{OC}$ are emitted together, although in different proportions depending on the source. Because the SLCF scenario focuses on BC-rich sources, the impact of OC emissions is relatively low in these scenarios, with the magnitude of the $\mathrm{OC}$ forcing differences (BCOC-EndU-reference) ranging from 10 to $20 \%$ of the $\mathrm{BC}$ forcing differences.

For the BCOC-EndU scenario, we define all forcing changes other than direct BC and $\mathrm{OC}$ to be auxiliary reductions. The largest auxiliary changes are cloud indirect effects, which act to reduce the forcing impact of the $\mathrm{BC}$ emission reductions while tropospheric ozone changes add to the forcing reductions. Overall, up until about 2050, auxiliary forcing changes are net positive, reducing the impact of the $\mathrm{BC}$ and OC forcing reductions by up to $50 \%$ (Fig. 3, Fig. S9, S10). Auxiliary forcing changes in the BCOC-EndU scenario generally peak in 2030 and decrease in absolute magnitude thereafter. The two models with the largest auxiliary forcing (DNE21+ and ENVLinkages) also have the largest reductions in $\mathrm{BC}$ forcing, so their total forcing impact is still among the highest among these models.

Note that one factor that was not included in these models was that the sulfur content of road diesel fuel would need to be reduced to very low levels in order to facilitate the operation of the particulate control devices necessary to achieve low $\mathrm{BC}$ emission levels from the transportation sector. This would further reduce the temperature impact of BC-focused reductions (Smith and Mizrahi 2013). Overall, given the role of auxiliary reductions, we conclude that it is important to include a comprehensive representation of air pollutant and GHG emission changes when examining the impact of potential BC-focused policies.

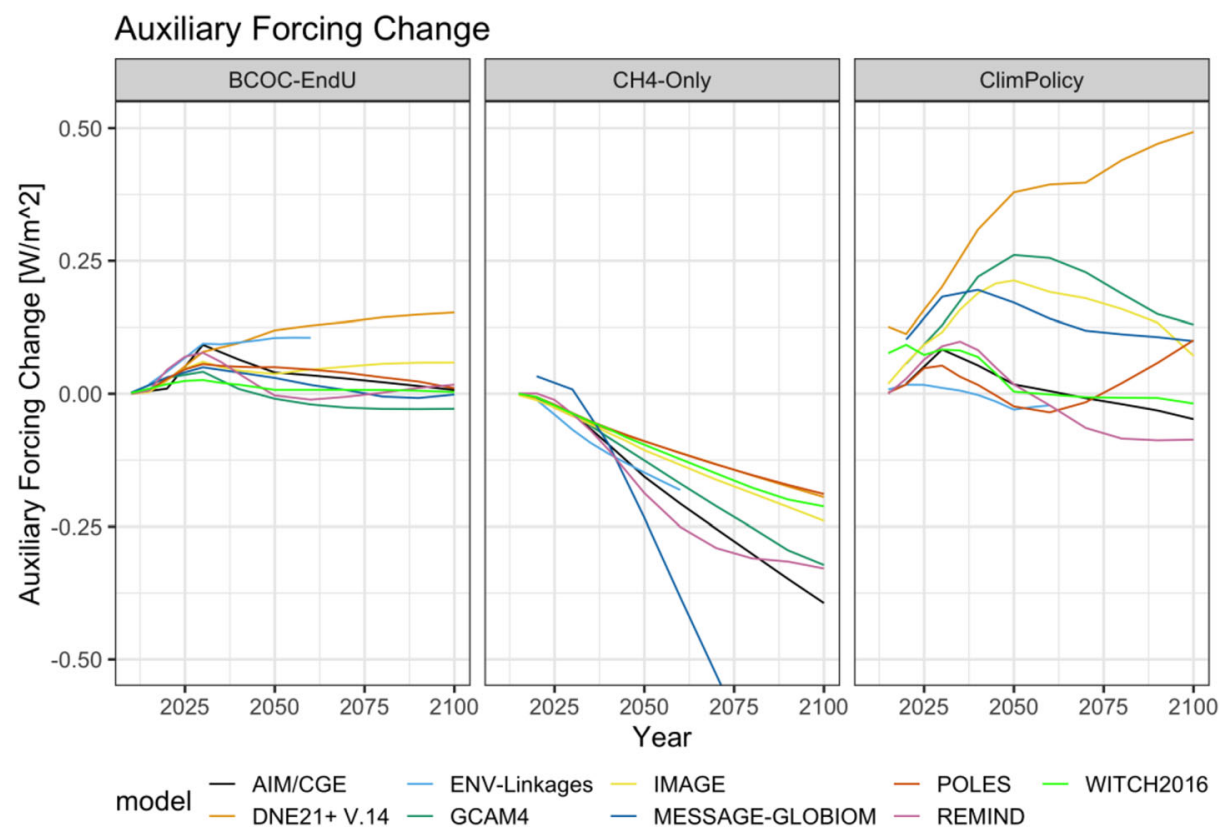

Fig. 3 Auxiliary radiative forcing changes - the sum of all forcing changes (e.g., Fig. 2, and SM figures) other than the primary target(s) of each policy (see text for definition) for the CH4-Only, BCOC-EndU, and ClimPolicy scenarios. Changes are expressed as absolute differences from the reference scenario 


\section{Temperature changes}

\subsection{Results using central climate model parameters}

As shown in Fig. 1b, the relative size of temperature changes generally mirrors that of the forcing changes, although there is not a 1:1 correspondence since greenhouse gases and aerosols have different efficacies and response timescales. Temperature reductions in the SLCF scenario show a relatively wide spread in 2030 , from $0.04-0.15^{\circ} \mathrm{C}$ below the reference scenario with the relative range narrowing by 2050 to $0.18-0.26^{\circ} \mathrm{C}$. The inter-model variation is largest for the $\mathrm{BC}$ reductions, with significant variation also in $\mathrm{CH}_{4}$ impacts.

In 2030, the contribution of $\mathrm{BC}$ emissions reductions ranges from 0 to $50 \%$ of the temperature change, depending on the model. The relative impact of the $\mathrm{BC}$ reductions is smaller by 2050 , with one set of models showing very little net contribution (AIM/CGE, IMAGE, WITCH), another set (DNE21+, GCAM4, ENV-Linkages) showing 20-30\% contribution, and the remainder showing a $10 \%$ contribution (POLES, MESSAGE-GLOBIOM, REMIND).

We can also examine the extent to which SLCF reductions might augment a climate policy by comparing temperature changes in the ClimPolicy scenario with those in the ClimPolicy+SLCF scenario (Fig. 4). Relative to the ClimPolicy scenario, the simultaneous SLCF policy results in additional cooling from $\mathrm{BC}, \mathrm{CH}_{4}, \mathrm{CO}_{2}$, and tropospheric ozone, offset by changes in cloud indirect and nitrate forcing (Fig. S15). The maximum additional benefit of the SLCF reductions, applied in addition to the comprehensive climate policy, is in 2040 for most models. The magnitude of the additional SLCF temperature reduction varies from near zero to $0.07^{\circ} / 0.08{ }^{\circ} \mathrm{C}$ in 2030/2040 (similar to that found in Harmsen et al. 2019b). This is much smaller than the reduction due to the SLCF policy in isolation, since much of the methane reductions and some of the $\mathrm{BC}$-oriented reductions also occur under a comprehensive climate policy. The SLCF policy has a larger relative impact at earlier times, but the absolute impact varies by model. By 2040, two models (AIM/CGE, WITCH) show almost no additional temperature benefit while the remainder finds $20-50 \%$ of SLCFonly temperature reduction still occurs if coupled with the climate policy scenario.

\subsection{Uncertainty analysis}

The above forcing and temperature results were generated using central assumptions for aerosol forcing and other climate system parameters. Aerosol forcing in particular is quite uncertain and this uncertainty will impact results. We conduct here an uncertainty analysis using the uncertainty range from a Monte Carlo setup of MAGICC6 following the approach outlined in Meinshausen et al. (2009), with the distribution of equilibrium climate sensitivity set to be consistent with the assessment of the Fifth Assessment Report of the Intergovernmental Panel on Climate Change as described in Rogelj et al. (2012, 2014a). The uncertainty analysis consists of 600 cases that sample across a range of 82 climate model parameters selected such that the model matches historical temperature change within a specified accuracy. The parameters varied including climate sensitivity, ocean heat diffusion rate, and strength of aerosol forcing by species (i.e., sulfate direct, BC direct, OC direct, cloud indirect) as detailed in Table S1 of Meinshausen et al. (2009). This parameter distribution, therefore, represents uncertainty in how the physical system would respond to changes in SLCF and 


\section{Change Relative to ClimPolicy for ClimPolicy+SLCF}

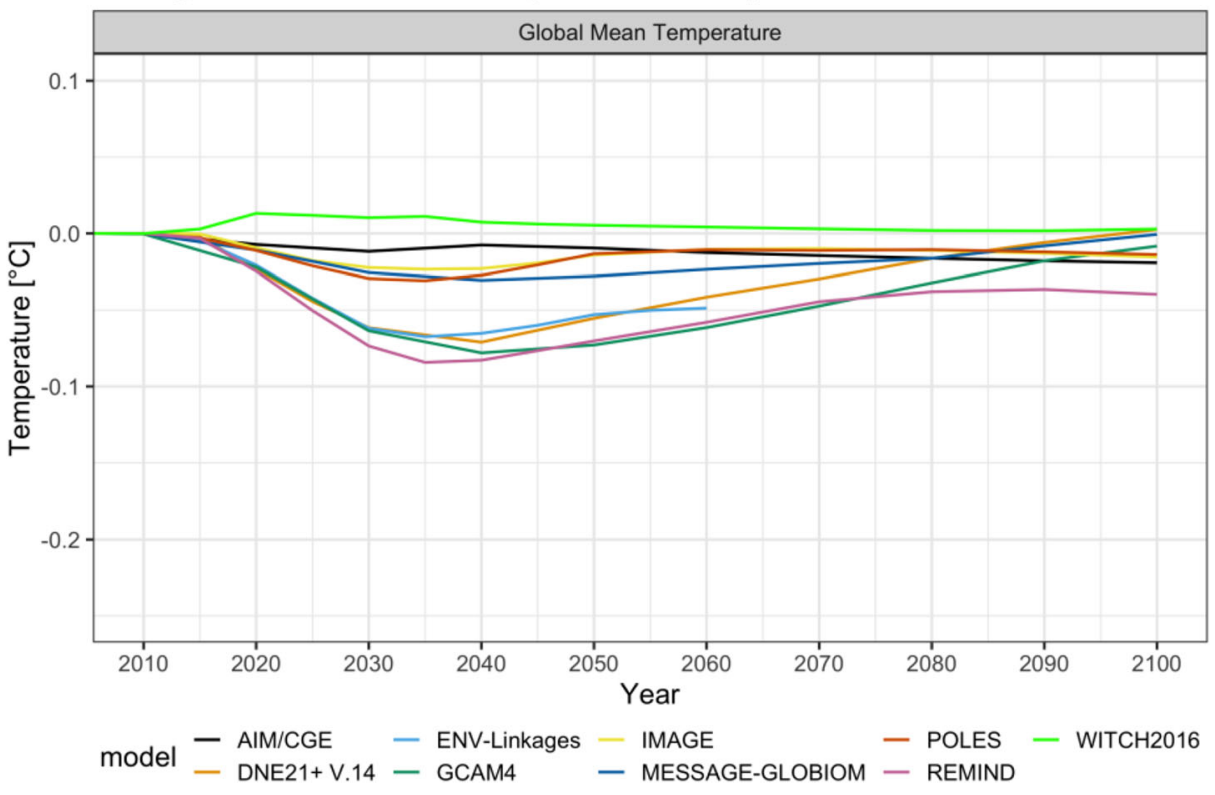

Fig. 4 Additional global temperature change due to SLCF emission reductions when applied to the ClimPolicy scenario for central climate model parameters (ClimPolicy+SLCF scenario-ClimPolicy scenario). Negative values represent an additional reduction in global temperature change due to the SLCF reductions.

GHG emissions, with parameter combinations constrained such that the results are consistent with historical observations.

As shown in Fig. 5, uncertainty in climate model parameters, primarily aerosol forcing strengths (see SM), result in a large temperature range, due to parametric uncertainty. Overall, this parametric uncertainty has a larger impact on results than the selection of an IAM. For example, the range in central temperature change relative to reference across the IAM models for the BCOC-EndU scenario is $0.12{ }^{\circ} \mathrm{C}$ (Fig. 1b), while the range in any single IAM model due to parametric uncertainty is $3-5$ times the range across IAMs.

We note that the parametric uncertainty range varies by a factor of 2 across models, or $0.29-0.60{ }^{\circ} \mathrm{C}$. The distribution is skewed with a tail of cases with temperature reductions that are more than twice the central value. The five parameters that most influence these high tail cases are as follows: ocean vertical diffusivity, climate sensitivity, methane forcing per unit concentrations, tropospheric ozone forcing, and the land/ocean warming ratio. The role of climate sensitivity is straightforward; this affects all results. The importance of the methane and ozone parameters is due to methane's role as the largest SLCF component and its role as a precursor of background tropospheric ozone. Both ocean diffusivity and the land/ocean contrast play key roles in determining climate response timescales. These parameters, therefore, determine how fast the climate system responds to a short-timescale forcing change (see SM for further details).

Note, however, that the larger temperature increases in the uncertainty analysis are often also associated with larger reference scenario temperature changes (Figs. S23-25). That means that these larger temperature reductions do not necessarily reflect a larger proportionate reduction in temperature change. The strength of the relationship between SLCF scenario 


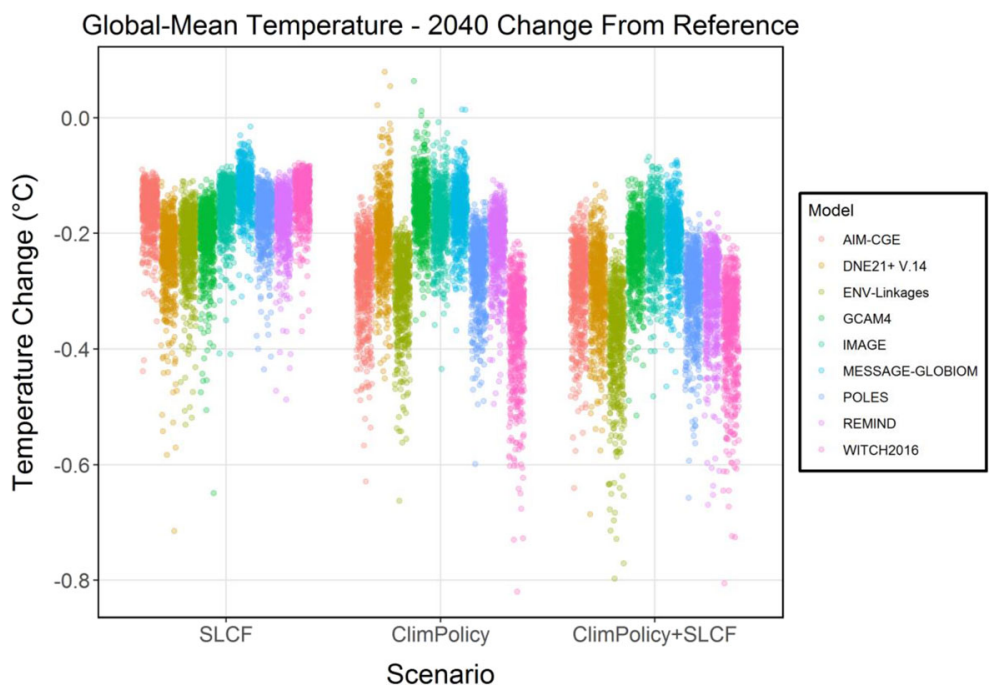

Fig. 5 Uncertainty analysis for 2040 temperature change, relative to reference scenario, by model. Each colored cloud represents results for the specified IAM sorted left to right and identified by color as indicated in the legend. These results are analogous to Fig. 1b but are showing the implications of climate parameter uncertainty. Horizontal jitter within results for each model added for clarity; only the vertical position of each point has meaning

reduction and reference case temperature varies by model, with the models with higher SLCF scenario reductions generally having a stronger relationship.

In 2030, the range in temperature reduction due to parametric uncertainty is similar for the SLCF and ClimPolicy scenarios, except that there are more cases with a near-term increase in global-mean temperatures for the ClimPolicy scenarios, i.e., a temporary dis-benefit. This is because, under a climate policy, there is a larger reduction in cooling from sulfur dioxide emissions (Fig. S13) compared with the SLCF scenario (Fig. S12). If cooling forcing per unit sulfate emissions is high, one of the possibilities covered in the uncertainty ensemble, then there is a possibility of a near-term temperature dis-benefit. By 2050, the parametric uncertainty range is much larger for ClimPolicy and there are no longer any cases with a dis-benefit (Fig. S22).

\section{Discussion}

Estimates of temperature reductions from SLCF scenarios relative to reference scenarios in 2050 ranged from $0.18-0.26{ }^{\circ} \mathrm{C}$ across the nine models (from $0.11-0.23{ }^{\circ} \mathrm{C}$ in 2040 ), using a central set of climate and aerosol assumptions. The models varied substantially in the extent to which $\mathrm{BC}$-focused mitigation contributed to this reduction while methane drives $70 \%$ or more of the temperature reductions by 2050 , which is consistent with previous studies.

We note that it is important to examine the effect of potential policy actions relative to realistic reference scenarios since background conditions such as GHG concentrations and air pollutant emissions will certainly change over time. Using a multi-model approach, we can better identify what results are robust with respect to differing energy-economic models. 
We also find that the economic assumptions related to how methane reductions are implemented in a model can have a large influence on the size of auxiliary forcing reductions, defined as forcing reductions from species other than those primarily targeted by the policy. Auxiliary reductions of carbon dioxide emissions play an increasing role as time goes on in models where the value of methane emissions is allowed to impact economic decision-making.

We find that there is a substantial overlap between a SLCF policy and a comprehensive climate policy that reduces greenhouse gas emissions. When both SLCF and GHG reduction policies are considered together, the additional benefit from a SLCF policy ranges from zero in some models to a maximum of $0.07^{\circ} / 0.08{ }^{\circ} \mathrm{C}$ in $2030 / 2040$ in other models. This is much smaller than the reduction from the SLCF-focused policy alone. We, therefore, find limited near-term additional global climate forcing reduction from SLCF-focused policies when combined with comprehensive GHG reductions in these scenarios.

These comparisons reinforce the importance of GHG-focused emission reductions, particularly $\mathrm{CO}_{2}$, for long-term temperature decreases relative to the reference scenario. The temperature impact of BC-focused emission reductions peaks in 2030-2040, while the impact of methane-focused reductions continues to increase through to 2100 (Fig. S18). However, only comprehensive GHG reductions produce temperature reductions relative to reference larger than $\sim 0.4{ }^{\circ} \mathrm{C}$ by 2050 (using central climate system parameters).

The temperature reduction is strongly dependent on uncertain climate model parameters. This parametric uncertainty is far larger than the differences between models. If climate sensitivity is high and methane and timescale-related parameters are in a certain range (see $\S 4.2$ and SM), then the SLCF scenario could reduce temperatures up to $0.5-1.0^{\circ} \mathrm{C}$ by 2050 for end-case parameter choices. On the other end of the uncertainty range, temperature reductions could be half of the central case results, or even result in additional warming.

Note that we have used a single simple climate model in this work. This model has been shown to provide results similar to an ensemble of more complex models (Meinshausen et al. 2011). With respect to SLCF scenarios, we note that the results of Stohl et al. (2015) using more complex models were nearly identical to those from Smith and Mizrahi (2013) using an earlier version of the MAGICC simple model used here. While our uncertainty analysis covers a range of parametric uncertainty, there is likely additional structural uncertainty due to the use of a single climate model.

We note in particular that there is substantial scientific uncertainty in the mechanisms by which black carbon emissions would impact surface temperatures, and this uncertainty is not necessarily reflected in current multi-model assessments or in the simple climate model used here. A set of experiments removing all anthropogenic BC from four coupled model simulations found temperature effects that were inconsistent both between models and between ensemble members of the same model (Baker et al. 2015). Recent work has noted that rapid adjustments to $\mathrm{BC}$-atmospheric effects act to reduce the net impact of black carbon on surface temperature (Stjern et al. 2017), leading the community toward the use of a new definition of radiative forcing that includes rapid adjustments. This might reduce estimates of BC temperature impact in future assessments; however, large differences between model responses remain. We also note that the temperature response to a change in $\mathrm{BC}$ emissions in the MAGICC6 model used here (Schwarber et al. 2018) is different in character to the response shown in a step emission experiments in two coupled climate model experiments (Sand et al. 2015; Yang et al. 2019), further emphasizing the uncertainty in climate responses to BC emissions in particular. Overall, therefore, results for the impact of black carbon on surface temperature should be considered indicative. 
We note also that changes in GHG and aerosol emissions will impact not only global meantemperature but also regional temperature changes and precipitation; however, methods to examine these changes in simple climate models do not yet exist and are, therefore, not addressed in this study.

Results for methane are more robust, although uncertainties remain (Harmsen et al. 2019b). Methane contributes the largest amount to temperature reduction in the SLCF scenarios considered here with central case temperature reductions of around $0.2{ }^{\circ} \mathrm{C}$ by mid-century. Recent findings (Etminan et al. 2016; Modak et al. 2018) suggest that a $\pm 14 \%$ uncertainty in methane efficacy may underestimate the uncertainty in methane forcing.

This analysis focused on the impacts of policy scenarios, that is, reductions as compared with a reference scenario produced by the same model. While we find a fair amount of consistency in the methane forcing reductions across models (Fig. 2), there is still a substantial range in the absolute level of emissions that remain after mitigation measures have been put into place. This is particularly true for methane. As noted in Harmsen et al. (2019a), there is a range of $\sim 150 \mathrm{Mt}$ in global methane emissions between models in both 2050 and 2100 even under strong methane mitigation assumptions. Lower methane emissions would both lower near-term climate change and also increase the allowable long-term carbon budget (Rogelj et al. 2018). Continued refinement of methane emission projections and mitigation potentials should remain an important area for future research. Given our findings on the impact of auxiliary reductions on forcing reductions from the stylized methane scenarios considered here, further consideration of how methane-focused reductions might be most realistically simulated in IAMs from an economic perspective is also warranted.

Author contributions SJS drafted the paper. KD, GL, and JR contributed analysis. All other authors conducted/contributed model results. All authors reviewed the manuscript.

Funding SJS was supported for this work by the U.S. Environmental Protection Agency. The authors are indebted to John Weyant and the Energy Modeling Forum for organizing this study. [For BATTELLE authors] Notice: This manuscript has been authored by Battelle Memorial Institute under Contract No. DE-AC0576RL01830 with the U.S. Department of Energy. The Department of Energy will provide public access to these results of federally sponsored research in accordance with the DOE Public Access Plan (http://energy. gov/downloads/doe-public-access-plan).

Open Access This article is licensed under a Creative Commons Attribution 4.0 International License, which permits use, sharing, adaptation, distribution and reproduction in any medium or format, as long as you give appropriate credit to the original author(s) and the source, provide a link to the Creative Commons licence, and indicate if changes were made. The images or other third party material in this article are included in the article's Creative Commons licence, unless indicated otherwise in a credit line to the material. If material is not included in the article's Creative Commons licence and your intended use is not permitted by statutory regulation or exceeds the permitted use, you will need to obtain permission directly from the copyright holder. To view a copy of this licence, visit http://creativecommons.org/licenses/by/4.0/.

\section{References}

Baker LH et al (2015) Climate responses to anthropogenic emissions of short-lived climate pollutants. Atmos Chem Phys 15:8201-8216

Bond TC et al (2013) Bounding the role of black carbon in the climate system: a scientific assessment. J Geophys Res Atmos 118:5380-5552. https://doi.org/10.1002/jgrd.50171

Boucher O, Friedlingstein P, Collins B, Shine KP (2009) The indirect global warming potential and global temperature change potential due to methane oxidation. Environ Res Lett 4 
Etminan M et al (2016) Radiative forcing of carbon dioxide, methane, and nitrous oxide: a significant revision of the methane radiative forcing. Geophys Res Lett 43

Harmsen M, Van Vuuren D, Bodirsky B, Chateau J, Drouet L, Fricko O, Fujimori S, Gernaat D, Hanaoka T, Hilaire J, Keramidas K, Luderer G, Moura MCP, Sano F, Smith SJ, Wada K (2019a) The role of methane in future climate strategies: mitigation potentials and climate impacts. Clim Change (this issue). https://oi. org/10.1007/s10584-019-02437-2

Harmsen M, Fricko O, Hilaire J, Van Vuuren D, Drouet L, Durand-Lasserve O, Fujimori S, Keramidas K, Klimont Z, Luderer G, Reis L, Riahi K, Sano F, Smith SJ (2019b). "Taking some heat off the NDCs? The limited potential of additional short-lived climate forcers' mitigation" Climatic Change (this issue). https://doi.org/10.1007/s10584-019-02436-3

$\mathrm{Hu} \mathrm{A}, \mathrm{Xu} \mathrm{Y}$, Tebaldi C, Washington WM, Ramanathan V (2013) Mitigation of short-lived climate pollutants slows sea-level rise. Nat Clim Chang. https://doi.org/10.1038/NCLIMATE1869

Luderer G, Vrontisi Z, Bertram C, Edelenbosch OY, Pietzcker RC, Rogelj J et al (2018) Residual fossil CO2 emissions in 1.5-2 ${ }^{\circ} \mathrm{C}$ pathways. Nat Clim Chang 8(7):626-633. https://doi.org/10.1038/s41558-018-0198-6

Meinshausen M, Meinshausen N, Hare W, Raper SC, Frieler K, Knutti R, Frame DJ, Allen MR (2009) Greenhouse-gas emission targets for limiting global warming to 2 C. Nature 458(7242):1158

Meinshausen M, Raper SCB, Wigley TML (2011) Emulating coupled atmosphere-ocean and carbon cycle models with a simpler model, MAGICC6 - part 1: model description and calibration. Atmos Chem Phys 11(4):1417-1456. https://doi.org/10.5194/acp-11-1417-2011

Modak A, Bala G, Caldeira K, Cao L (2018) Does shortwave absorption by methane influence its effectiveness? Clim Dyn 51(9-10):3653-3672

Myhre G et al (2013) Anthropogenic and natural radiative forcing. In: Stocker TF, Qin D, Plattner G-K, Tignor M, Allen SK, Boschung J, Nauels A, Xia Y, Bex V, Midgley PM (eds) Climate Change 2013: The Physical Science Basis. Contribution of Working Group I to the Fifth Assessment Report of the Intergovernmental Panel on Climate Change. Cambridge University press, Cambridge

O’Neill BC et al (2017) The roads ahead: narratives for shared socioeconomic pathways describing world futures in the 21 st century. Glob Environ Chang 42:169-180

Ramanathan V, Xu YY (2010) The Copenhagen accord for limiting global warming: criteria, constraints, and available avenues. Proc Natl Acad Sci U S A 107:8055-8062

Rogelj J, Schaeffer M, Meinshausen M, Shindell DT, Hare W, Klimont Z, Velders GJM, Amann M, Schellnhuber HJ (2014a) Disentangling the effects of CO2 and short-lived climate forcer mitigation. Proc Natl Acad Sci 111:16325-16330

Rogelj J, Shindell D, Jiang K, Fifita S, Forster P, Ginzburg V, Handa C, Kheshgi H, Kobayashi S, Kriegler E, Mundaca L, Séférian R, and Vilariño MV, (2018): Mitigation pathways compatible with $1.5^{\circ} \mathrm{C}$ in the context of sustainable development. In: Global Warming of $1.5^{\circ} \mathrm{C}$. An IPCC Special Report on the impacts of global warming of $1.5^{\circ} \mathrm{C}$ above pre-industrial levels and related global greenhouse gas emission pathways, in the context of strengthening the global response to the threat of climate change, sustainable development, and efforts to eradicate poverty [Masson-Delmotte, V., P. Zhai, H.-O. Pörtner, D. Roberts, J. Skea, P.R. Shukla, A. Pirani, W. Moufouma-Okia, C. Péan, R. Pidcock, S. Connors, J.B.R. Matthews, Y. Chen, X. Zhou, M.I. Gomis, E. Lonnoy, T. Maycock, M. Tignor, and T. Waterfield (eds.)]. (published on-line. https://www.ipcc. ch/sr15/. Last accessed: 5/29/2020.)

Sand M, Iversen T, Bohlinger P, Kirkevåg A, Seierstad I, Seland Ø, Sorteberg A (2015) A standardized global climate model study showing unique properties for the climate re- sponse to black carbon aerosols. J Clim 28:2512-2526. https://doi.org/10.1175/JCLI-D-14-00050.1

Schwarber ASJ Smith CA Hartin BA, Vega-Westhoff A and Sriver R. 2018. Evaluating climate emulation: fundamental impulse testing of simple climate models. Earth System Dynamics (in review)

Shindell D (2014) Inhomogeneous forcing and transient cli- mate sensitivity. Nat Clim Chang 4:274-277. https://doi.org/10.1038/nclimate2136

Shindell D, Kuylenstierna JCI, Vignati E, van Dingenen R, Amann M, Klimont Z, Anenberg SC, Muller N, Janssens-Maenhout G, Raes F, Schwartz J, Faluvegi G, Pozzoli L, Kupiainen K, Hoglund-Isaksson L, Emberson L, Streets D, Ramanathan V, Hicks K, Oanh NTK, Milly G, Williams M, Demkine V, Fowler D (2012) Simultaneously mitigating near-term climate change and improving human health and food security. Science 335(6065):183-189

Smith SJ, Mizrahi A (2013) Near-term climate mitigation by short-lived forcers. Proc Natl Acad Sci 110:1420214206

Stjern CW et al (2017) Rapid adjustments cause weak surface temperature response to increased black carbon concentrations. J Geophys Res Atmos 122(11):462-11,481

Stohl A et al (2015) Evaluating the climate and air quality impacts of short-lived pollutants. Atmos Chem Phys 15:10529-10566. https://doi.org/10.5194/acp-15-10529-2015 
Rogelj J, Meinshausen M, Knutti R (2012) Global warming under old and new scenarios using IPCC climate sensitivity range estimates. Nat Clim Chang 2(4):248

Rogelj J, Meinshausen M, Sedláček J, Knutti R (2014b) Implications of potentially lower climate sensitivity on climate projections and policy. Environ Res Lett 9(3):031003

Yang YSJ, Smith H, Wang CM, Mills CM, Rasch PJ (2019) Variability timescales and non-linearity in climate responses to black carbon emissions. Atmos Chem Phys 19:2405-2420. https://doi.org/10.5194/acp-192405-2019

UNEP (2011) Near-term climate protection and clean air benefits: actions for controlling short-lived climate forcers. United Nations Environment Programme (UNEP), Kenya

Publisher's note Springer Nature remains neutral with regard to jurisdictional claims in published maps and institutional affiliations.

\section{Affiliations}

Steven J Smith ${ }^{1} \cdot$ Jean Chateau ${ }^{2} \cdot$ Kalyn Dorheim $^{1} \cdot$ Laurent Drouet $^{3} \cdot$ Olivier $^{-}$ Durand-Lasserve $^{2}$ - Oliver Fricko ${ }^{4}$. Shinichiro Fujimori ${ }^{5,6} \cdot$ Tatsuya Hanaoka $^{6}$ - Mathijs Harmsen $^{7,8}$ • Jérôme Hilaire ${ }^{9,10}$ - Kimon Keramidas ${ }^{11}$ • Zbigniew Klimont ${ }^{4}$ - Gunnar Luderer $^{9}$ - Maria Cecilia P. Moura ${ }^{1} \cdot$ Keywan Riahi ${ }^{4}$ • Joeri Rogelj ${ }^{12,4}$ • Fuminori Sano ${ }^{13}$. Detlef P. van Vuuren ${ }^{7,8} \cdot$ Kenichi Wada ${ }^{13}$

1 Joint Global Change Research Institute, Pacific Northwest National Laboratory, 5825 University Research Court, Suite 3500, College Park, MD 20740, USA

2 OECD Environment Directorate, 2 rue André Pascal, 75116 Paris, France

3 RFF-CMCC European Institute on Economics and the Environment (EIEE), Centro Euro-Mediterraneo sui Cambiamenti Climatici, Via Bergogne 34, 20144 Milan, Italy

4 International Institute for Applied Systems Analysis (IIASA), Schlossplatz-1, A-2361 Laxenburg, Austria

5 Department of Environmental Engineering, Kyoto University, C1-3-361, Katsura-Campus, Nishikyo-ku, Kyoto City 615-8540, Japan

6 Center for Social and Environmental Systems Research, National Institute for Environmental Studies, 16-2 Onogawa, Tsukuba, Ibaraki 305-8506, Japan

7 PBL Netherlands Environmental Assessment Agency, Bezuidenhoutseweg 30, 2594 AV The Hague, The Netherlands

8 Copernicus Institute for Sustainable Development, Utrecht University, Princetonlaan 8a, 3584 CB Utrecht, The Netherlands

9 Potsdam Institute for Climate Impact Research (PIK), Leibniz Association, P.O. Box 6012 03, 14412 Potsdam, Germany

10 Mercator Research Institute on Global Commons and Climate Change (MCC), Torgauerstrasse 12, 10829 Berlin, Germany

11 Joint Research Centre of the European Commission, Edificio Expo, Calle Inca Garcilaso, 3, 41092 Sevilla, Spain

12 Grantham Institute for Climate Change and the Environment, Imperial College, London SW7 2AZ, UK

13 Research Institute of Innovative Technology for the Earth (RITE), 9-2, Kizugawadai, Kizugawa-Shi, Kyoto 619-0292, Japan 